\title{
Experimental analysis of prepreg tack
}

\author{
O. Dubois, J.-B. Le Cam and A. Béakou \\ Laboratoire de Mécanique et Ingénieries (LaMI)UBP/IFMA \\ Campus de Clermont-Ferrand / les Cézeaux \\ B.P. 265 F-63175 Aubière cedex, France
}

March 5, 2009

\begin{abstract}
A probe tack test apparatus is designed to characterize the tack of carbon-epoxy prepreg. Tests are performed on both pure resin and prepreg. The maximum debonding force seems to be a relevant measure of tack. First, results show that the response of pure resin is similar to that of viscous silicon oil. Second, the shape of the response curve obtained for prepreg beyond the maximum value of the debonding force is mainly due to structural effects. Third, the influence of contact force, contact time, debonding rate, probe temperature and ageing conditions on the prepreg tack is investigated in relation with physical phenomena involved in the debonding phase.
\end{abstract}

Keywords: Epoxy, Interfaces, Probe tack test, Prepreg

\section{Introduction}

Composite materials are increasingly used in the design of structural parts, particularly in the aerospace industry where weight is of primary importance. One way of manufacturing complex composite materials components is to use prepreg materials. In this case, tack is one of the major properties that governs the ability of prepreg to be laid up. Therefore, the tack of prepreg has to be characterized to improve the manufacturing of such complex composite materials. However, tack measurement remains an open problem. Difficulties encountered lie in the meaning of tack. In fact, the tack of a material can be estimated by the sensation one experiences when removing one's finger from any sticky material [1]. Quantifying this feeling remains a problem since strength and debonding energy come into play. Moreover, these two quantities do not necessarily evolve in the same way when test parameters are changed. For the composite community, tack is the property required to produce a sufficient bond between adjacent prepreg plies, but not too high so that a misplaced prepreg ply can be relocated [2]. This definition is similar to pressure sensitive adhesives 
(PSA) requirements. However, due to the existence of reinforcing fibres, prepreg tack is more complicated than adhesive tack.

There are different ways to measure prepreg tack. In industry, tack measurement is basically performed using the method described in ref. [3]. In this study, a prepreg specimen is applied with light pressure to a support or another prepreg specimen in a vertical position at room temperature. The tack is considered acceptable if the prepreg specimen remains in position for a specified duration. A second way to measure the tack of prepreg deals with the so-called peel test that consists in progressively removing one sticky material from another [4]. A strip of the material to be characterized, with a flexible backing if necessary, is applied on a substrate, which may be a rigid plate or another flexible strip. One extremity of the backing is then pulled off to debond the material from the adherend. The debonding force measured for a specified angle, a specified rate and a specified width of strip is considered as a measure of tack. Contact time is generally long and to obtain reproducible results the contact area between the peeling strip and the material should be carefully controlled. Moreover, the response measured is the average of all phenomena involved in adherence. On the other hand, the peel angle influences the loading mode (tensile/shear ratio), but the fabric stiffness limits the experimental domain, so the loading mode is almost limited. In fact, due to the fabric stiffness, if the peel angle is high, the interface between the prepreg and the support can fail instantaneously without peeling.

The most appropriate tack measurement seems to come from the works dealing with pressure sensitive adhesives $[5,6,7,8,9]$. It is called probe tack test and consists of a probe that comes into contact with the material to characterize, is then removed from it and the force and/or energy of separation is measured. In this case, contact formation and separation phases are clearly dissociated, so the contact parameters are easy to control, and each step of debonding can be clearly observed. Moreover, the confinement of the material (height/width ratio) can be set, so it is possible to decide whether to give precedence to surface contributions in respect to volume contributions or not [5].

In the literature, a few studies deal with the prepreg tack $[2,10,11,12]$, but to our knowledge, only one study investigates the tack of prepreg using the probe tack test [12]. The challenge in this study is to develop a suitable tack measurement apparatus such as the probe tack test which provides quantitative data on the tack of prepreg to exhibit the influence of the test parameters.

\section{Experimental section}

In this section, the material used and the sample geometry are first presented. Second, the method used to measure the tack is detailed and finally loading conditions and environmental parameters applied are summarized. 


\section{Material and samples}

The material considered here is M21/35\%/268/T700GC prepreg provided by Hexcel Composites (Dagneux, France). It is composed of unidirectional carbon fibres (T700GC provided by Toray) and resin (M21 resin). This epoxy resin contains thermoplastic matrix phases. Figure 1 presents the sample geometry of prepreg, which corresponds to a small strip $20 \mathrm{~mm}$ wide by $60 \mathrm{~mm}$ long. Only one side of the prepreg is protected by a release paper. Due to the surface tension, the resin content is higher on this side than on the opposite side and consequently, this phenomenon involves a change in tack between the two sides. For this reason, tests are always carried out on the same side, opposite to the release paper.

As the tack of prepreg is given by that of resin, it is also necessary to perform the test on the pure resin. For that purpose, the sample used for testing the tack properties of resin, shown in Figure 2 corresponds to a $20 \mathrm{~mm}$ diameter pancake. Its height varies between 250 and $300 \mu \mathrm{m}$.

\section{Tack measurement}

Tack measurement was performed using the same technique used for pressure sensitive adhesives, i.e. the probe tack test. For that purpose, a $1 k N$ Instron 5543 universal testing machine (Norwood, MA, USA) was used with a software which allowed us to define the specific cycle corresponding to the probe tack test. Figure 3 shows this apparatus. The upper grip was replaced by an aluminium cylindrical probe of $10 \mathrm{~mm}$ diameter mounted on the moving crosshead of the machine, via a $50 \mathrm{~N}$ capacity load cell. The probe can be heated with a flexible heater. A PT100 temperature sensor linked to a Proportional-IntegralDerivative (PID) temperature controller allowed us to regulate the temperature. It had been validated that the probe should be designed in such a way that the temperature of its extremity connected to the load cell would remain inferior to $35^{\circ} C$ when a $80^{\circ} C$ temperature was imposed at the other extremity. This ensures that the load cell stays in the temperature range in which it is compensated.

Figure 4 presents the probe and the lower support. The probe inclination was set using a goniometric plateau to make its contact surface parallel to that of the lower support. Once the prepreg was applied on the lower support, the probe, which was surrounded by a heater, was set at a given temperature, then the probe came into contact with the prepreg. Besides, it was possible to put a camera under this support (when transparent) to observe phenomena occurring during the test and to link them to different parts of the response curve.

Finally, a climatic chamber allowed us to change the temperature and relative humidity of the air surrounding samples during the ageing phase. Relative humidity is denoted $R H$ in the following.

The test procedure used for the tack measurement is described hereafter:

1. Prepreg strips or resin films were cut in order to obtain the abovementioned geometry. Samples were then put in a climatic chamber for a given 
time at controlled temperature and $R H$.

2. Before each run, the contact surface of the probe and the support were cleaned with acetone.

3. Contact time, contact force and debonding rate were set for the mechanical cycle.

4. The temperature of the probe was set in a regulator.

5. Once the temperature of the probe reached the set point and was equilibrated, the sample was removed from the climatic chamber and was positioned on the support. It should be noted that the side of the prepreg protected by a release paper, i.e. the tackiest side, was applied without pressure on the lower grip.

6. The value given by the load cell was reset and the test started. Time, force and crosshead displacement were then measured.

\section{Loading and environmental conditions}

In order to characterize the tack of prepreg and to highlight the influence of loading and environmental conditions, selected parameters were investigated. The range of variation of their values is summarized in Table 1.

\section{Results}

As explained above, the response of resin has to be characterized using the probe tack test before that of prepreg. To compare results obtained for both resin and prepreg, resin has to be in the same state as that in prepreg. For that reason, resin was directly taken from the prepreg production line. In the following, the results obtained on resin are first presented, and second those obtained on prepreg are more precisely detailed related to the variation of test parameters. It should be noted that the debonding force is normalized by the value of the maximum of the debonding force reached throughout the tests and denoted $F_{r e f}$. Its value is equal to $28.19 \mathrm{~N}$.

\section{Pure resin}

Results obtained on the resin using the probe tack test lead to a typical response of the material that is presented in Figure 5. In this figure, the evolution of the debonding force versus displacement is given for a resin film whose thickness is equal to $0.3 \mathrm{~mm}$, i.e. approximately the thickness of prepreg. Here, the displacement is measured by the displacement sensor of the testing machine that gives the displacement of the moving grip. Tests were carried out at $32{ }^{\circ} \mathrm{C}$ probe temperature, $30 \mathrm{~s}$ contact time, $30 \mathrm{~N}$ contact force, $5 \mathrm{~mm} / \mathrm{min}$ debonding rate and $35 \%$ ambient hygrometry. 
In this figure, the response of the resin can be cut up into the following four parts:

- part $[\mathrm{OA}]$ : the force rapidly increases with the displacement of the probe until it reaches a maximum value at point A;

- part $[\mathrm{AB}]$ : from the maximum value, the force begins to decrease. This is explained by the fact that cavities appear and grow in the bulk material due to both the high level of hydrostatic pressure and the multiaxial character of the stress.

- part $[\mathrm{BC}]$ : in this part of the curve, the force decreases more rapidly than in the previous part. It corresponds to the penetration of the air in the cavities which, until then, were mostly under vacuum. This has been pointed out by Teisseire and co-workers in ref. [13], by Poivet and coworkers in ref. [14] but has also been observed by Tirumkudulu and coworker [15]. It should be noted that this phenomenon was observed even if the probe is stopped during the cavity extension phase. This is due to the liquid behaviour of the material $[16,17]$, which flows and cannot resist indefinitely the increase in pressure gradient between inside and outside the cavities;

- part [CD]: the shape of the previous cavities evolves while they are uniaxially stretched; their walls relax and/or fail, and the force measured slowly returns to zero.

The previous description of the force-displacement response of the resin can be compared to those of PSA and viscous silicon oil (VSO). The reader can refer to the works of Creton [5, 8] for PSA and Teisseire [18] for VSO. Figure 6 and Figure 7 illustrate the schematic response to the probe tack test performed on PSA and VSO, respectively. In a similar way to the curve obtained for resin, the response of such materials can also be cut up into several parts. The first part $[\mathrm{OA}]$ corresponds to the rapid increase of the force. The maximum value of the force is reached at point A. Then, cavitation occurs in the bulk material. For PSA material, the cavity growth is firstly isotropic (part [AB]) and cavity walls are uniaxially stretched (part $[\mathrm{BC}]$ ). For this material, the fact that a plateau is observed indicates that fibrillation occurs. For VSO material, cavities grow laterally, i.e. perpendicular to the stretch direction (part $[\mathrm{AB}]$ ), before being stretched in the direction of stretch (part $\left.\left[\mathrm{BB}^{\prime}\right]\right)$. Then, penetration of the air in the cavities occurs (part $\left[\mathrm{B}^{\prime} \mathrm{C}\right]$ ). Finally, part $[\mathrm{CD}]$ corresponds either to the failure of the walls cavities or to debonding between PSA and probe or support, or to viscous deformation of VSO until failure of the cavity walls. In our case, the viscosity and the physical mechanisms observed in resin lead us to compare the behaviour of such a material with that of VSO materials rather than that of PSA materials.

As presented before, the curve that gives the evolution of the force versus the displacement allows us to correctly describe the physical phenomena involved 
in the deformation of resin. However, the measurement of the tack of resin in not discussed here.

\section{Prepreg}

\section{Structural effects}

Figure 8 presents typical curves obtained by performing a probe tack test on three prepreg specimens under the same test conditions: $25 \mathrm{~N}$ contact force and $60 \mathrm{~s}$ contact time. In a similar way to resin, each of these curves exhibits the same shape of the first part corresponding to a rapid increase of the force until it reaches a maximum value (part $[\mathrm{OA}]$ for resin, Figure 5). However, the shape of the second part of the present curves differs from one to the others and strongly differs from that of resin (parts $[\mathrm{AB}],[\mathrm{BC}]$ and $[\mathrm{CD}]$, Figure 5). This is mainly due to structural effects involved in the addition of fibres to the resin. Indeed, contrary to the resin response, that of prepreg corresponds to the average of local responses.

Some phenomena due to the addition of fibres can be listed:

- fibres at the interface between probe and prepreg generate a surface roughness different from that of resin;

- the resin content varies from point to point. More particularly, the resin distribution at the interface between probe and prepreg is not uniform. That affects the contact formation. In these conditions, contact formation evolves with time, the applied force and the temperature during the contact phase;

- the manufacturing process involves a gradient of resin content between the surface and the middle of the strip. This gradient is favorable to delamination. Moreover, the contact phase may modify the gradient if resin moves through the bulk material;

- the resin located between fibres corresponds to a thin film that is not subjected to phenomena that occur classically in the bulk resin such as cavitation for instance.

These reasons explain why the shape of the second part of the curve obtained for prepreg differs from that obtained for the resin. In fact, the failure mechanisms evolve with the test parameters. This will be discussed in the following. Moreover, as shown in Figure 8, for the same test conditions applied to several prepreg specimens, the shape of the second part of the curves also differs from one to the next. As the shape of the first part of the curve is not affected by the test parameters nor by the structural effects, the maximum value of the debonding force seems to be a relevant indicator of the prepreg tack. 


\section{Influence of the test parameters}

In this section, the influence of the test parameters as contact time, contact force level, probe temperature and the debonding rate on tack is investigated. Here, we also study the influence of ageing conditions such as hygrometry and ageing time.

\section{Influence of contact time and contact force}

As mentioned above, the distribution of resin content can first lead to incomplete contact. So, the maximum of the contact surface is obtained once the contact time is applied and the contact force set. To investigate the influence of the contact time and the contact force on prepreg tack, several probe tack tests were carried out and here, only the maximum debonding force is used for the analysis. As explained previously, the maximum debonding force and the maximum debonding energy evolve in the same way. Figure 9 shows the evolution of the maximum debonding force with the contact time. In this figure, the maximum of the debonding force increases with the contact time and the contact force. Each curve obtained exhibits a linear part from a contact time equal to $30 \mathrm{~s}$. The fact that the relation between the maximum debonding force and the contact time is not linear before $30 \mathrm{~s}$ should be explained by a non-complete contact. Figure 10 can be deduced from Figure 9 to highlight the evolution of the maximum debonding force with the contact force. As expected, the maximum debonding force increases with the contact force and the contact time and the threshold from which the relation between the maximum debonding force and the contact force becomes linear corresponds to a $15 \mathrm{~N}$ contact force. It should be noted that these results are obtained for a $30{ }^{\circ} \mathrm{C}$ probe temperature and a $5 \mathrm{~mm} / \mathrm{min}$ debonding rate. In the following, the influence of these parameters will be investigated.

This behaviour is different from that observed by Creton et al. [5] because of the difference in test procedure. In our experiments, the tests were carried out under prescribed contact force whereas those of Creton et al. were performed under constant probe displacement. In the former case, increasing the contact time allows the material relaxation to increase. As mentioned by the authors, relaxation leads to a longer fibrillation phase and so to greater debonding energy. In the present study, only creep is generated during the contact phase and contact time does not influence significantly the debonding force after complete contact formation.

As a summary, these results highlight a threshold from which the maximum debonding force is less dependent on the contact time and the contact force, from $30 s$ for the contact time and from $15 N$ for the contact force. From these values, it becomes easy to analyse the influence of the different test parameters. In the next section, these parameters are set at $30 s$ or $60 s$ and $30 \mathrm{~N}$ respectively.

\section{Influence of probe temperature}

Figure 11 shows the evolution of the maximum debonding force versus probe temperature for $5 \mathrm{~mm} / \mathrm{min}$ debonding rate, $60 \mathrm{~s}$ contact time and $30 \mathrm{~N}$ contact 
force. Here, the maximum debonding force decreases in a monotonic way with the temperature. Temperature increase changes the resin properties, more particularly it decreases the resin viscosity and allows the resin to migrate within the prepreg thickness. As a consequence, the resin content at the probe-prepreg interface decreases and that of the inner interfaces increases. Thus, the debonding force decreases and the delamination phenomenon observed during debonding is reduced.

\section{Influence of ageing conditions}

Figure 12 shows the evolution of the debonding force with ageing time. Here, ageing was performed at $20^{\circ} \mathrm{C}$ by applying two levels of relative humidity; 20 and $80 \%$. For the present probe tack tests, the contact force and the contact time were set at $30 \mathrm{~N}$ and $30 \mathrm{~s}$ respectively, the debonding rate was set at $5 \mathrm{~mm} / \mathrm{min}$ and the probe temperature was equal to $30^{\circ} \mathrm{C}$. First, this figure shows that the maximum debonding force slightly decreases with the ageing time. Second, this figure also shows that increasing relative humidity leads to a decrease in the maximum debonding force. The latter result is still not explained and further works are currently being carried out to investigate this phenomenon.

\section{Influence of debonding rate}

Previously, the contact time was set at $30 s$ to investigate the influence of the ageing conditions. The contact time was set at $60 \mathrm{~s}$ to investigate the influence of the probe temperature in order to ensure that the contact surface at the interface between the prepreg and the probe remains at its maximal value at low probe temperature. For this value of contact time, fibrillation phenomenon was observed for temperatures greater or equal to $40^{\circ} \mathrm{C}$. To investigate the influence of the debonding rate on the failure mode (with or without fibrillation), the tests were performed with the test parameters which led to fibrillation $\left(40^{\circ} \mathrm{C}\right.$ temperature and $60 \mathrm{~s}$ contact time). Then, the debonding rate was increased. Figure 13 shows the evolution of the maximum debonding force with the probe debonding rate. In this figure, the maximum debonding force increases as the debonding rate increases. Here, two parts can be identified in relation with the debonding rate. Between 0 and $10 \mathrm{~mm} / \mathrm{min}$ the maximum debonding force increases significantly. From $10 \mathrm{~mm} / \mathrm{min}$, a change in the curve slope is observed and the maximum debonding force increases less rapidly. This change in the curve slope can be discussed in relation with the fibrillation phenomenon. Our experimental observations have therefore shown that no fibrillation occurs for a debonding rate superior to $10 \mathrm{~mm} / \mathrm{min}$.

\section{Conclusion}

In this study, a probe tack test has been designed to quantitatively characterize the prepreg tack. The maximum debonding force was chosen as a measure of tack to investigate the influence of loading and environmental conditions. 
Tack measurement was performed on both pure resin and prepreg. As can be seen, the response of pure resin is similar to that of viscous silicon oil whereas the response of prepreg strongly depends on structural effects. The results obtained highlight a threshold from which the maximum debonding force is less dependent on the contact time and the contact force, from $30 \mathrm{~s}$ for the contact time and from $15 \mathrm{~N}$ for the contact force. Moreover, the temperature increase changes the resin properties, more particularly it decreases the resin viscosity and allows the resin to migrate within the prepreg thickness. As a consequence, the resin content at the probe-prepreg interface decreases and that of the inner interfaces increases. Thus, the debonding force decreases and the delamination phenomenon observed during debonding is reduced. As expected, the maximum debonding force increases as the debonding rate increases. Moreover, the fibrillation phenomenon is observed for the lowest debonding rate. Above about $10 \mathrm{~mm} / \mathrm{min}$ no fibrillation is observed and the curve slope decreases. In conclusion, this study leads to some critical issues. Indeed, our first results on the influence of relative humidity are still not explained. In addition, intrinsic parameters such as the local content of resin and its distribution seem to play a role in the material tack. Further works are currently being carried out in our laboratory to investigate the influence of such parameters.

\section{Acknowledgements}

This work was supported by FERMAT project of the cluster AESE (Aéronautique, Espace et Systèmes Embarqués). The authors are grateful to Hexcel Composites, Airbus and Forest Liné Capdenac for their collaboration.

\section{References}

[1] Ondarçuhu T (1997). Tack of Polymer Melt: Adhesion Measurements and Fracture Profile Observations. J Phys II France 7:1893.

[2] Ahn KJ, Seferis JC, Pelton T, Wilhelm M (1992). Analysis and characterization of prepreg tack. Polym Composite 13:197.

[3] Cole KC, Noël D, Hechler JJ, Cielo P, Krapez JC, Chouliotis A, Overbury KC (1991). Room-Temperature Aging of Narmco 5208 Carbon-Epoxy Prepreg: Part II - Physical, Mechanical, and Nondestructive Characterization. Polym Composite 12:203.

[4] Banks R, Mouritz AP, John S, Coman F, Paton R (2004). Development of a new structural prepreg: characterisation of handling, drape and tack properties. Compos Struct 66:169.

[5] Creton C, Fabre P (2002). Tack. Adhes Sci Eng 1:535.

[6] Shull KR, Creton C. (2004). Tack. J Polym Sci B Polym Phys 42:4023. 
[7] Léger L, Creton C (2008). Adhesion mechanisms at soft polymer interfaces. Phil Trans Roy Soc London, Series A 366:1425.

[8] Josse G, Creton C, Dorget M (2001). Estimation des contributions de surface et de volume à l'adhésion des adhesifs mous PSA. Proceedings $11^{\text {th }}$ Journées d'Etude sur l'adhésion (Lège-Cap Ferret, France).

[9] Zosel A (1992). Fracture Energy and Tack of Pressure Sensitive Adhesives. Advances in Pressure Sensitive Adhesive Technology 1:92.

[10] Ahn KJ, Seferis JC, Pelton T, Wilhelm M (1992). Deformation parameters influencing prepreg tack. Sampe Quarterly 23:54.

[11] Ahn KJ, Peterson L, Seferis JC, Nowacki D, Zachmann HG (1992). Prepreg aging in relation to tack. J Appl Polym Sci 45:399.

[12] Gillanders AM, Kerr M, Martin TJ (1981). Determination of prepreg tack. Int J Adhes Adhes 1:125.

[13] Teisseire J, Nallet F, Fabre P, Gay C (2007). Understanding crack versus cavitation in pressure-sensitive adhesives: the role of kinetics. J Adhesion 83:613.

[14] Poivet S, Nallet F, Gay C, Fabre P (2003). Cavitation-induced force transition in confined viscous liquids under traction. Europhys Lett 62:244.

[15] Tirumkudulu M, Russell WB, Huang T (2003). On the measurement of "tack" for adhesives. J Phys Fluids 15:1588.

[16] Lakrout H, Creton C, Ahn D, Shull KR (2004). Influence of Molecular Features on the Tackiness of Acrylic Polymer Melts. Macromolecules 34:7448.

[17] Schach R, Creton C (2008). Adhesion at interfaces between highly entangled polymer melts. J Rheol 52:749.

[18] Teisseire J (2006). Tack de matériaux modèles. PhD Thesis Université Bordeaux I . 


\section{$\underline{\text { List of Figures }}$}

Figure 1: Prepreg M21/35\%/268/T700GC strip

Figure 2: Resin M21 pancake

Figure 3: Tensile testing machine with accessories

Figure 4: Details of the probe

Figure 5: Typical normalized force-displacement curve obtained for resin M21

Figure 6: Form of the response curve obtained when performing probe tack test on pressure sensitive adhesives

Figure 7: Form of the response curve obtained when performing probe tack test on a viscous silicon oil

Figure 8: Typical normalized force-displacement curves obtained for three prepreg specimens under the same test conditions $(25 \mathrm{~N}$ contact force and $60 \mathrm{~s}$ contact time)

Figure 9: Evolution of the maximum debonding force versus contact time; $30^{\circ} \mathrm{C}$ probe temperature, $5 \mathrm{~mm} / \mathrm{min}$ debonding rate and contact force between $5 \mathrm{~N}$ and $30 \mathrm{~N}$

Figure 10: Evolution of the maximum debonding force versus contact force; $30^{\circ} \mathrm{C}$ probe temperature, $5 \mathrm{~mm} / \mathrm{min}$ debonding rate and contact time between $1 \mathrm{~s}$ and $60 \mathrm{~s}$ 
Figure 11: Evolution of the maximum debonding force versus probe temperature; $5 \mathrm{~mm} / \mathrm{min}$ debonding rate, $60 \mathrm{~s}$ contact time and $30 \mathrm{~N}$ contact force

Figure 12: Evolution of the maximum debonding force versus ageing time, for two ageing conditions: (o) $20^{\circ} \mathrm{C}-80 \% R H ;(\triangle) 20^{\circ} \mathrm{C}-20 \% R H ; 5 \mathrm{~mm} / \mathrm{min}$ debonding rate, $30 \mathrm{~s}$ contact time and $30 \mathrm{~N}$ contact force

Figure 13: Evolution of the maximum debonding force versus debonding rate; $40^{\circ} \mathrm{C}$ probe temperature, $60 \mathrm{~s}$ contact time and $30 \mathrm{~N}$ contact force

Table 1: Parameters tested in the tack tests

\begin{tabular}{lll}
\hline Parameter category & Parameter & Range tested \\
\hline Environmental parameters & Relative humidity & $20-80 \%$ \\
& Ageing time & $0-2000 \mathrm{~min}$ \\
\hline Test parameters & Contact force & $1-30 \mathrm{~N}$ \\
& Contact time & $1-60 \mathrm{sec}$ \\
& Debonding rate & $0.5-50 \mathrm{~mm} / \mathrm{min}$ \\
& Probe temperature & $21-66^{\circ} \mathrm{C}$ \\
\hline
\end{tabular}




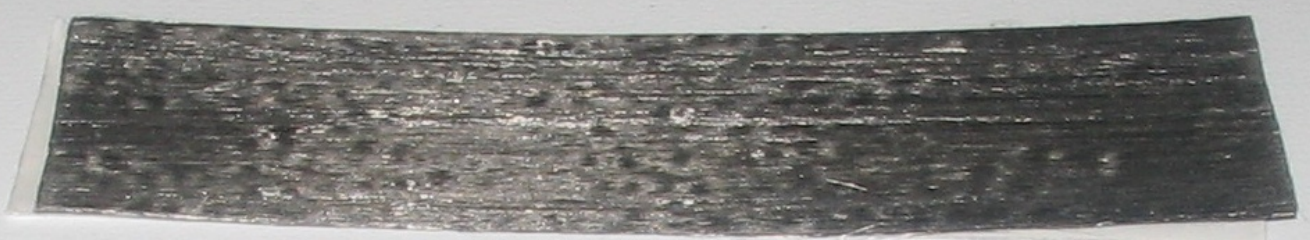

\section{$10 \mathrm{~mm}$ \\ $\longmapsto$}


$10 \mathrm{~mm}$ 



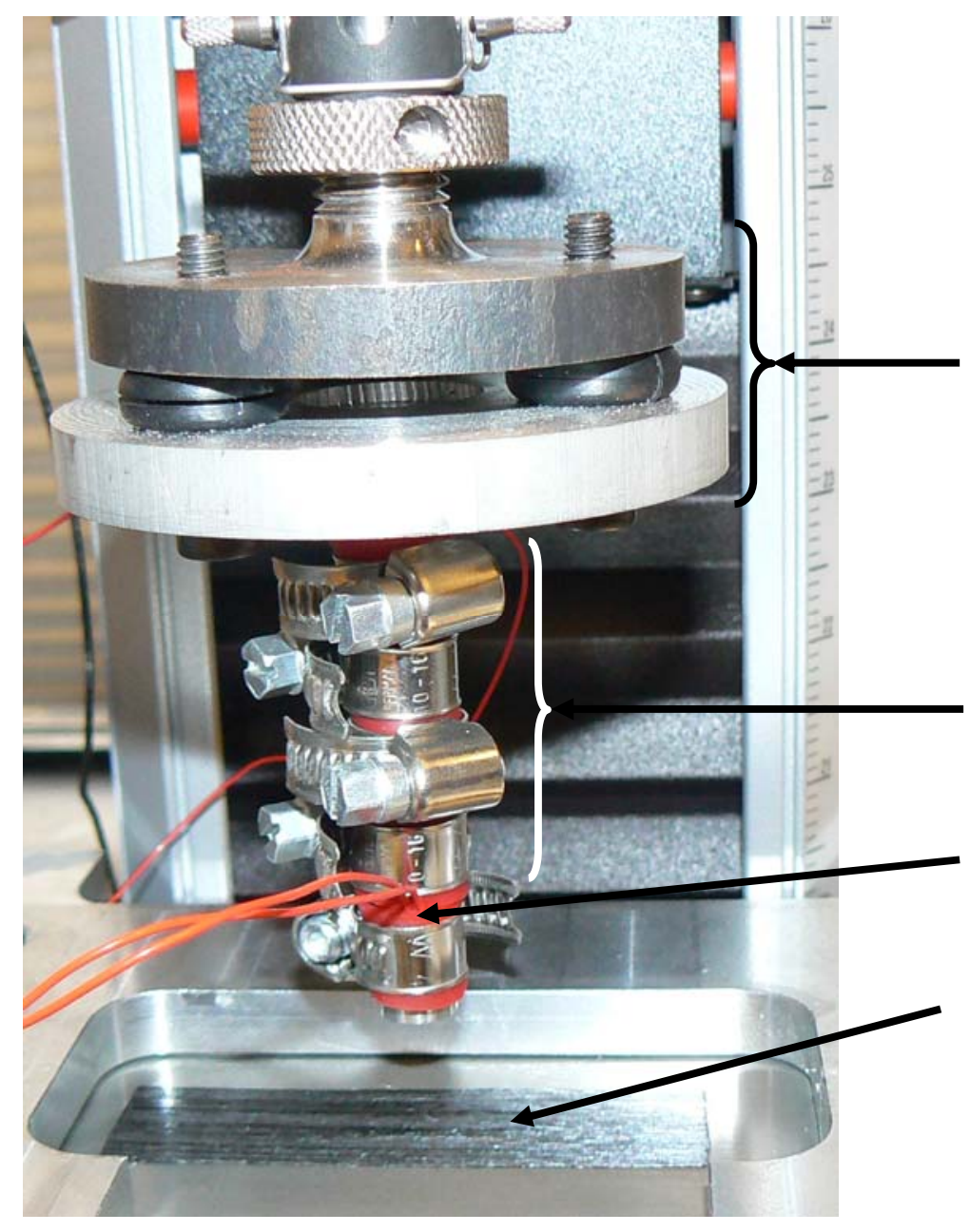

Goniometric plateau

Heater encircling the probe

Temperature sensor

Prepreg sample 
B

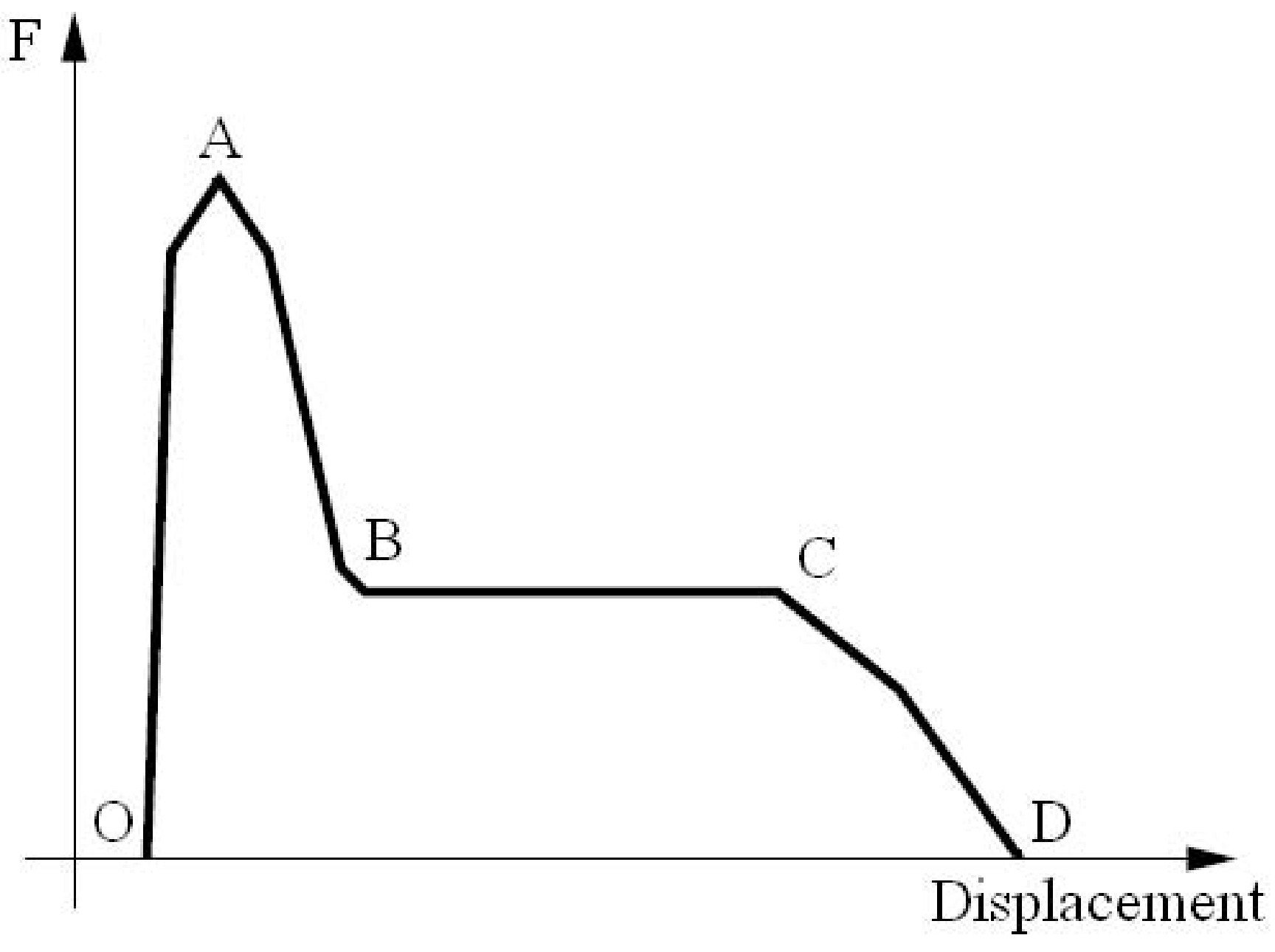

A

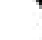


$\mathrm{F}$

B

$B^{\prime}$

C

Displacement

O

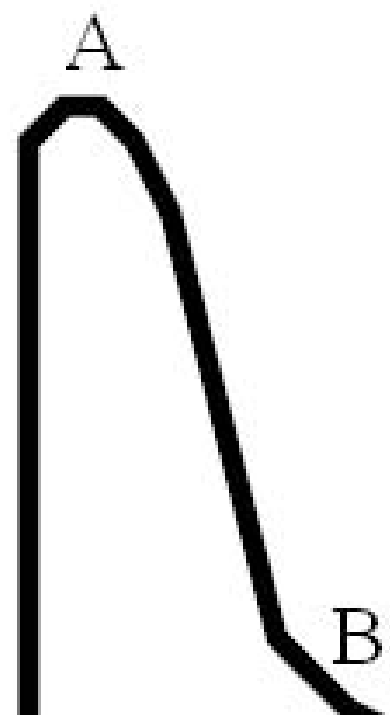

$+$

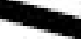

$\sim^{D}$ 


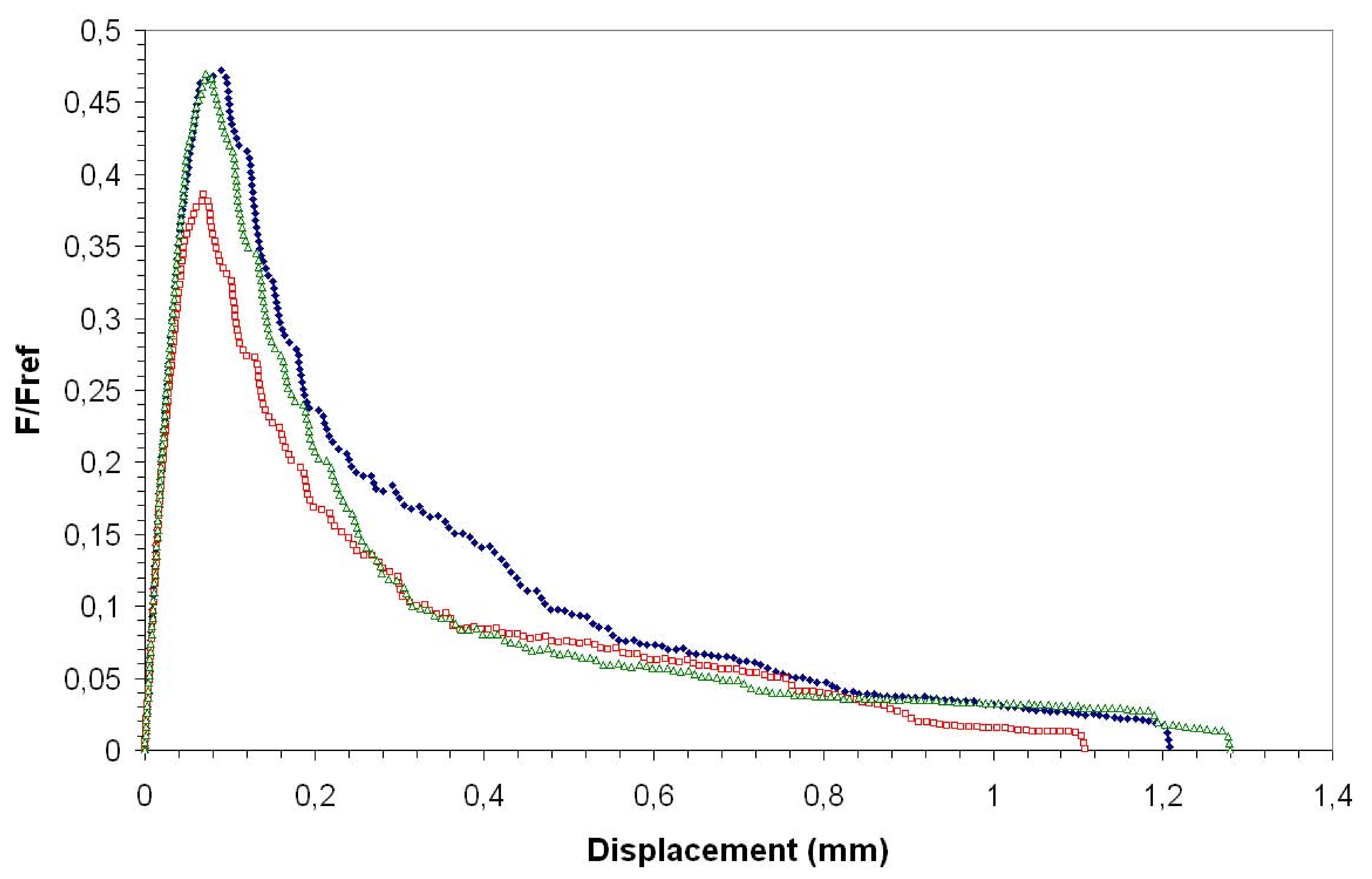




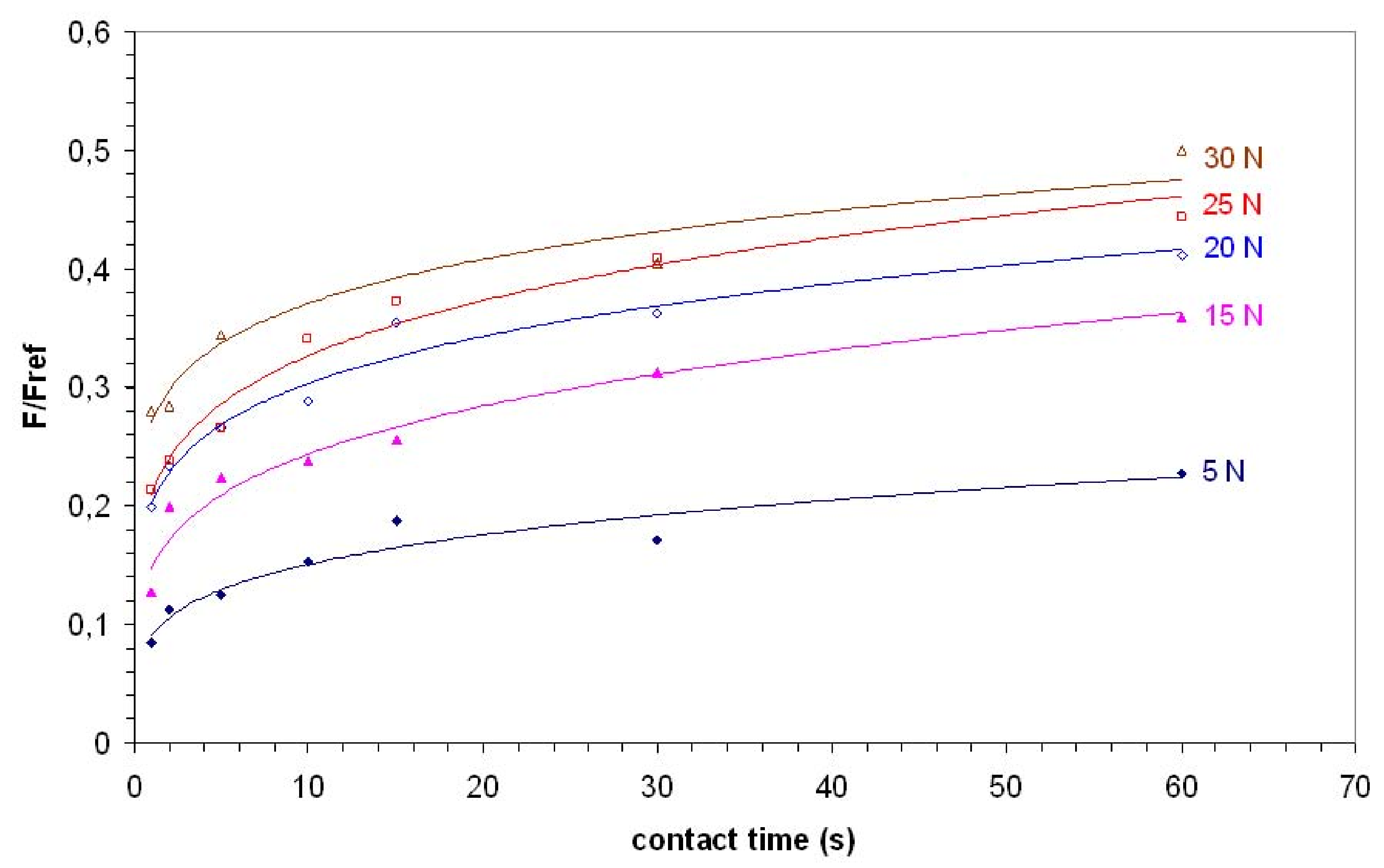




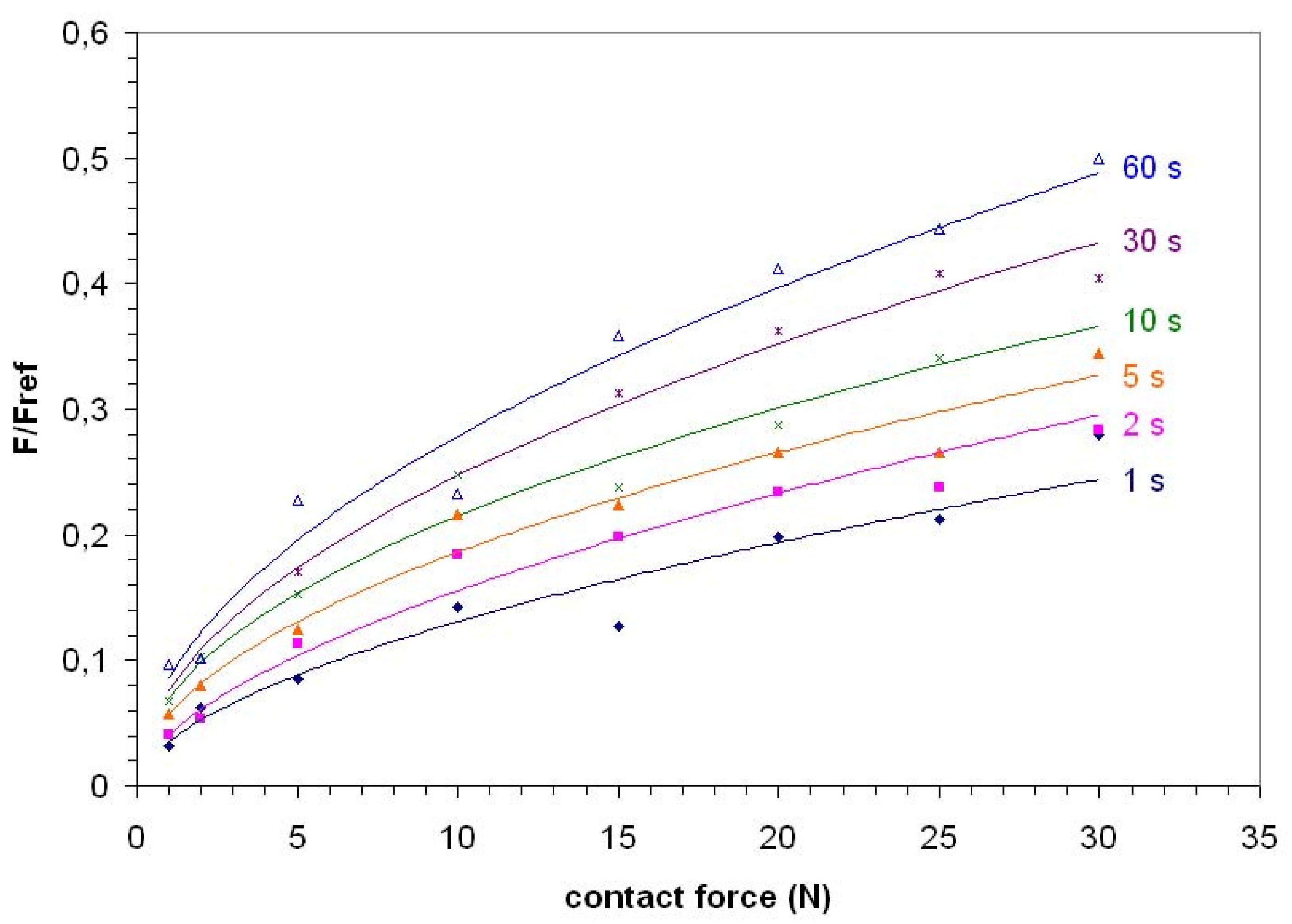




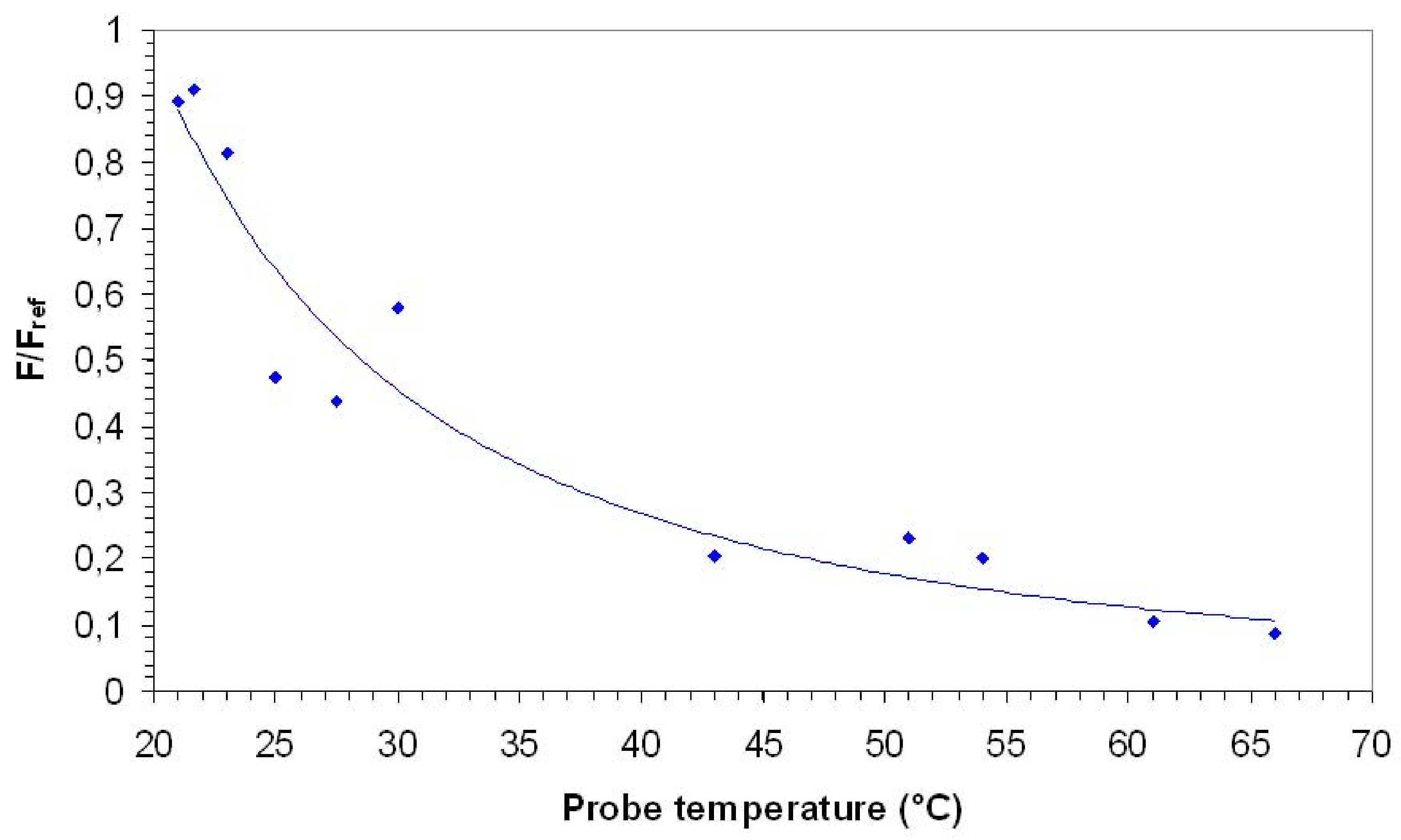




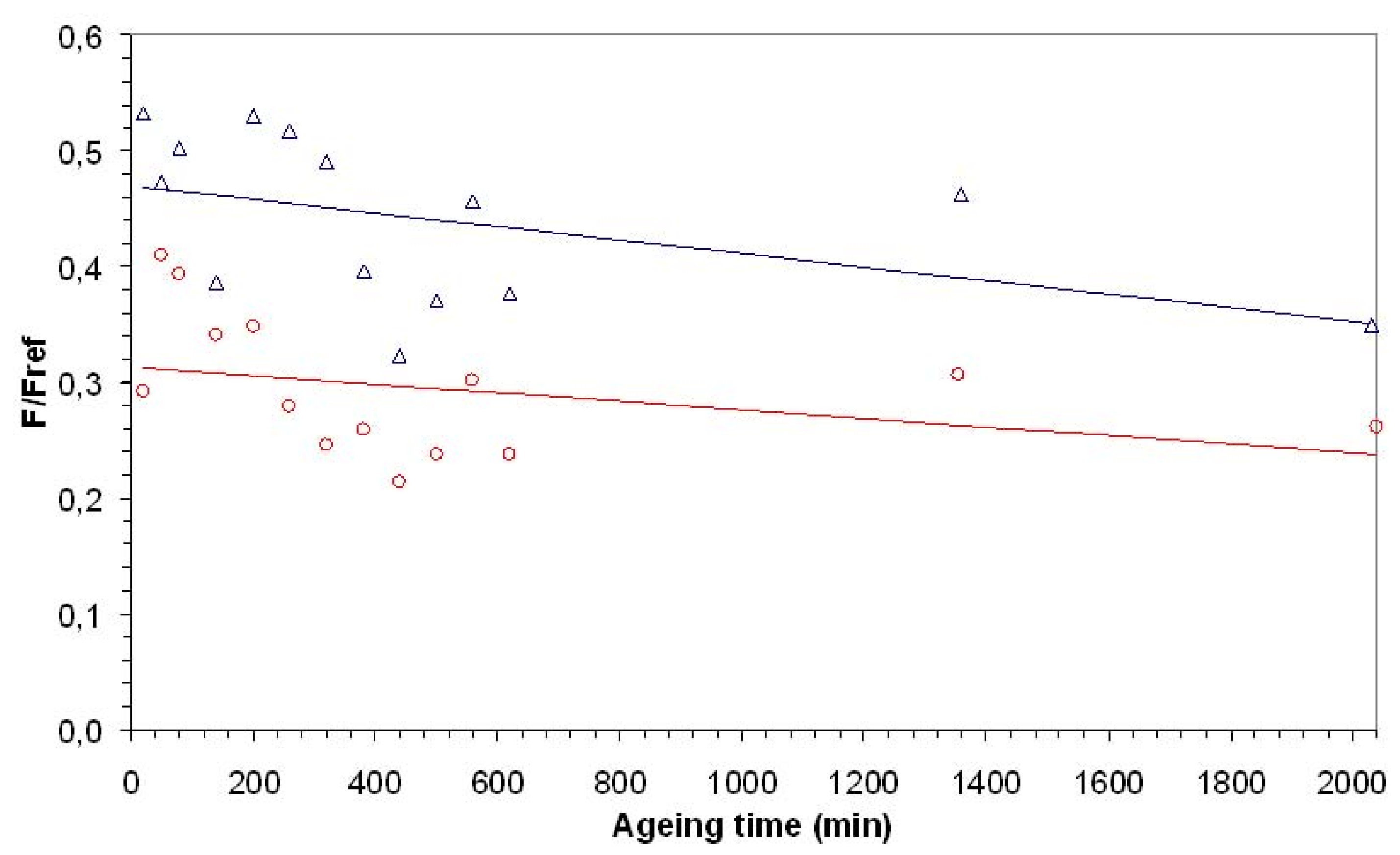




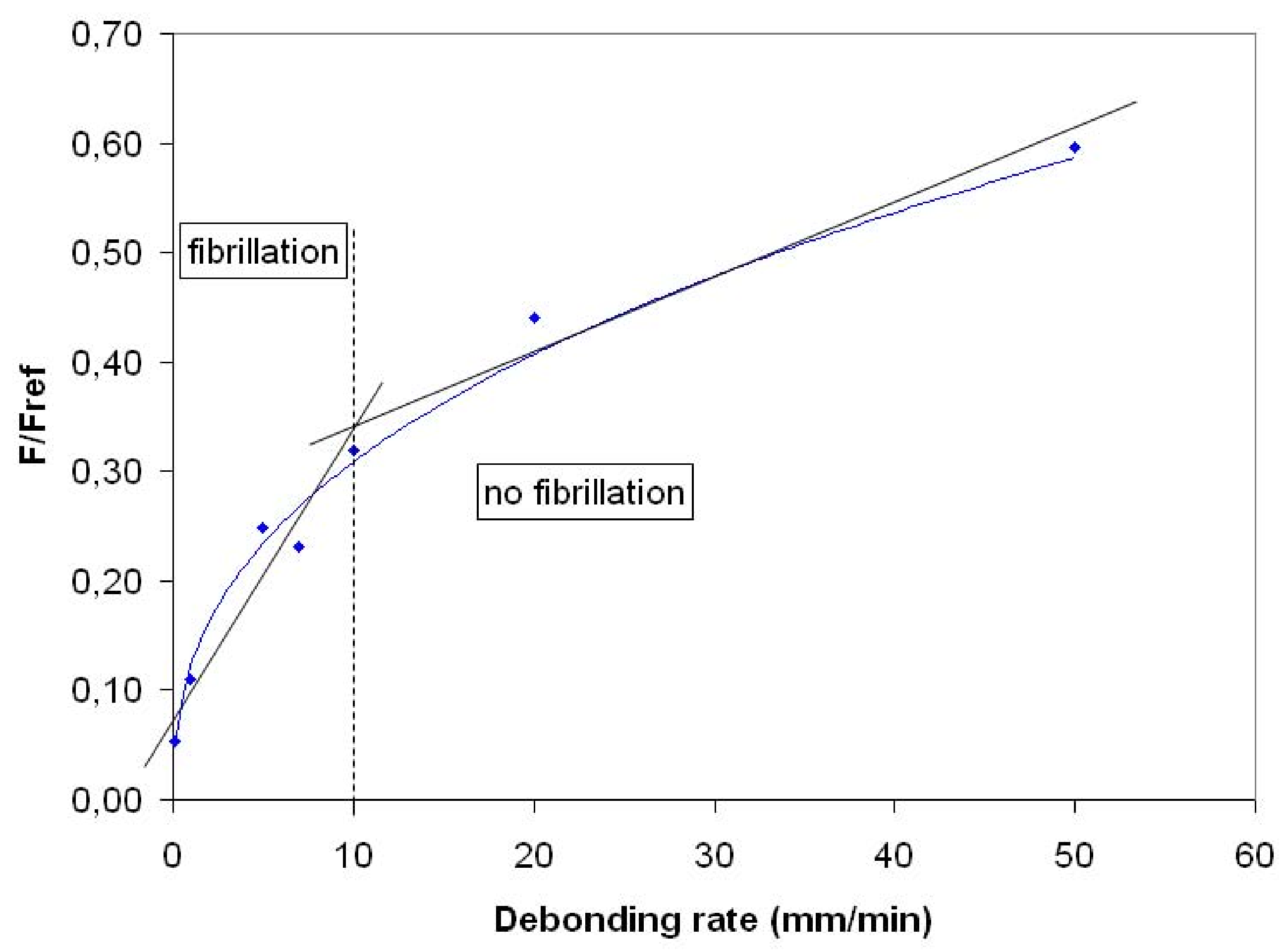

